\title{
Stratums of Members of Local Internet Communities: Main Features and Characteristics
}

\author{
Olga Ergunova, and Alexey Skuratov* \\ Department of integrated marketing communications and branding, 91944 UrFU, Russian Federation
}

\begin{abstract}
The article examines aspects of network societies functioning, describes characteristics of stratified scales in local Internet communities. The study of various aspects of stratification in virtual groups is based on a practical social research aimed at social and stratification analysis of local Internet communities existing in the cyber domains of large Russian cities. On the basis of generalization of theorizes and processing of the data received, the authors come to the conclusion that there is a stratified scale in any local community, according to which the users are ranged. The diversity of the entire system of criteria for status and role stratification, the skills of community members in applying these criteria influence the moderation rights used by the formal and informal leaders of the network community, and ultimately influence the controllability of interaction within the virtual group. Stratification within local virtual groups is systemic, since in the absence of it a social order is impossible. However, the stable functioning of the Internet community is not possible without a stratified system as a form of institutionalization of social action.
\end{abstract}

\section{Introduction}

Due to the absence of a theoretical description of information stratification in the study of networking cooperation, it is necessary to adapt models used for research of the offline world. Within the conditions of functioning of network societies, information stratification is organized irrespective of the presence of purposeful control or manipulation; it becomes a constituent element of virtual Internet communities [3, 9]. The results of the research, conducted by the authors through online and expert surveys, of the opinions of the members of local virtual groups on the specifics of the stratified structure of the Internet community showed the presence of stratification in them. The object of the study was the members of current virtual Internet communities localized within large Russian cities. In order to clarify stratified structure, a sociological standardized online survey for a wide range of members of virtual Internet community was held. The study involved the most experienced members-experts, as well as members who recently joined local Internet communities. A sample size was 345 people. The sample type is accidental. Secondary analysis of the data of social research was conducted by foreign and domestic authors: the results of research conducted by Internet companies Rambler and Yandex, data of the "Enterpulse" company, reports of the research company "eTForecast", studies of the fund "Public Opinion" and the working group "EITO Task Force" as well as the works of individual researchers A.A. Ivanov, D. Stanton, P. Collock, A.S. Aladyshkina,
G. Ravid, I. Yamodo, A.V. Chugunov, Sh. Rafaeli, V.L. Silaeva, K. Gusman, M. A. Smith and others.

According to the survey conducted by the authors, the absolute majority of the members of local Internet community (more than $70 \%$ ) clearly mark the presence of a hierarchical structure within local network societies (see Figure 1).

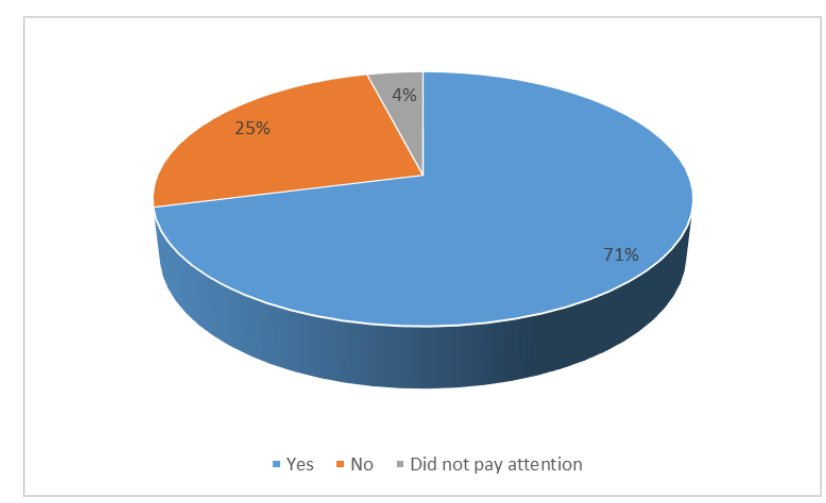

Fig. 1. Ratio of respondents by marking hierarchy in communication ( $\%$ to number of respondents).

In addition to it, all expert moderators, interviewed by the authors in the same way, positively stated the presence of the hierarchy even in such communication and liberal environment. Only new members absolutely wrongly consider the Internet community as a platform where everyone is equal and where it is possible to express their position familiarly and unreasonably. In the study of networking, most scientists use the class approach; however, in our opinion, this approach is

*Corresponding author`s: o.t.ergunova@urfu.ru, alexey.skuratov@urfu.ru 
unjustified: the features of the network group exclude ranking on a class basis [1]. It is explained by the fact that class inequality is leveled in the Internet environment; however, social ranking upon other criteria (for example, by the criterion of the right of access to information) is not excluded. Information stratification is organized regardless of the targeted control or manipulation; it becomes a constituent element of virtual Internet communities. If the processes of information stratification contribute to self-organization of community members, then integrating processes contribute to sustainability of the social structure.

\section{Literature Review}

Leading Western sociologists (Castells; Wellman; Rainie) consider the structure of online communities to be network on the basis of its organization and members relations. These researchers consider the structure of online communities as part of global process of social changes, the key feature of which is the transition from territorial communities and groups to networks as the basis of sociality. This model is based on the concept of network individualism, implying that horizontal relations, based on the equality of the members and freedom of communication, predominate in the Internet space. The consequence of the spread of the Internet within this theory is the smoothing of social inequality, and the consequence of networked individualism is the formation of egalitarian online communities, communities without hierarchy [5]. The result of spread of Internet within this theory is smoothing of social inequality, and the result of network individualism is formation of egalitarian online communities, communities without hierarchy. As an example illustrating the idea of an egalitarian online community, Wikipedia authors' communities often volunteer to collaborate with each other to write and edit articles in the web encyclopedia. An example illustrating the idea of an egalitarian online community is Wikipedia authors' communities, which cooperate with each other to write and edit articles in web encyclopedia. There is an alternative point of view according to which social stratification and hierarchical relations underlie the online communities (Reid; O'Neil; Christmas). Another research perspective, closely related to the study of the structure of communities, is online leadership topic where certain results have already been achieved (Hogan; Huffaker; Probst). The objectives of online leadership research are to identify influential or dominant users and explain their leading role through other characteristics of online behavior. The results of research in this area can also be interpreted in terms of the problem of social inequality in online communities, since the phenomenon of leadership involves the division of members into influential and others. The researcher of new media and virtual communities Christian Fuchs, researcher of new media and virtual communities, pays attention to rivalry and cooperative relations, which also characterize the social space and structure of online communities. At the present stage of research there is a shift in the parameters that determine derivation of benefits, from the material characteristics of access to the Internet to the differences in its use, skills and goals of users. At the same time, researchers of digital inequality, which open ever deeper levels of the gap, track off the circumstance of differentiation and stratification of users within online communities.

\section{Methodological approaches to selection of principles of social stratums classification}

The sociological community has developed two basic methodological approaches to the selection of principles of social stratums classification, relating to the social inequality analysis.

The first approach, founded by M. Weber, determines the statuses according to the characteristics chosen by the researcher himself (indicators of power, education, etc.). Quantitative indicators, at the same time, are self-contained, which excludes the need to take into account the sources of status differences[4].

The second approach is directly related to the study of stratification in the field of intercommunications of the active elements of social structure. The analysis of status positions in this case is carried out on the basis of creation of stratified scales of virtual communities. Showed causes allow carrying out practical studies of the absolute majority of local virtual communities, regardless the subject area to which a particular community is dedicated. The authors use this approach in the study of local virtual groups [6].

In such case, the authors pay attention to local Internet communities, social structure of which is based on the stratification principle. The criterion of information stratification is both the right to use certain media, and the right to fill the local Internet community with content. The most significant unit of stratification in a virtual group is the terminological pair of status-role. The application of status-role positions for research purposes is a multifaceted approach both in terms of physical, real, and virtual information environment. Here it is well worth to refer to Tolcott Parsons, who wrote, "Stratification in its evaluation aspect is ... ranking of units of the social system with the help of standards of the acknowledged evaluation system" [7]. The difference in capabilities is significantly characterized by the users' statuses specifics associated with the scope of power. These powers characterize the possibility of some members of a virtual group to influence on the behavior of other members of the local Internet community. If this stratification structure is institutionalized, then such relations can be terminologically defined as "authority". It should be noted that the specific forms of influence allowed, for example, to moderators of virtual groups, cannot be used by common members of local Internet communities $[8,10]$.

However, this fact does not exclude the existence in the network of various options for status protection against undesirable influences - the rights of members of virtual groups. 


\section{Model of stratified scale in local virtual group}

The authors integrated research data and proposed a model of stratified scale for local virtual group. Various local online communities have similar stratified systems and, in general, it is possible to present a stratified scale as follows:

- owners of Internet community;

- creators of electronic, software resources and content;

- members of Internet community, users.

Let us consider each of the indicated stratums in more detail. Stratum "owners of Internet community" is characterized by factors, specified in Table 1 .

Table 1. Characteristics of the stratum "owners of Internet community".

\begin{tabular}{|c|c|}
\hline \multicolumn{2}{|c|}{ Factors } \\
\hline objective & subjective \\
\hline right of property & $\begin{array}{c}\text { sense of special "power" } \\
\text { in relation to the existence } \\
\text { of a local virtual society }\end{array}$ \\
\hline $\begin{array}{c}\text { right to receive various } \\
\text { commercial benefit } \\
\text { creation of global } \\
\text { "information society" }\end{array}$ \\
\hline $\begin{array}{c}\text { presence of a significant } \\
\text { amount of power over the } \\
\text { virtual network group and } \\
\text { network resources specified } \\
\text { in regulatory documents }\end{array}$ & $\begin{array}{c}\text { presence of interest on the } \\
\text { part of the media to } \\
\text { Internet resources owned } \\
\text { by the said actor }\end{array}$ \\
\hline
\end{tabular}

The owner of the Internet community, proceeding from the scope of his powers, often has a determining and key influence on the specifics of the stratified structure of any local virtual group.

The next stratum is "creators of software resources and content". It includes users who are to some extent involved in the long term operation of the Internet community, as well as in the creation and placement of content. This stratum is characterized by the factors, specified in Table 2.

Table 2. Characteristics of stratum "creators of software resources and content".

\begin{tabular}{|c|c|}
\hline \multicolumn{2}{|c|}{ Factors } \\
\hline objective & subjective \\
\hline $\begin{array}{l}\text { participation in arranging } \\
\text { and maintaining of Internet } \\
\text { community }\end{array}$ & $\begin{array}{c}\text { sense of participation in } \\
\text { the creation of } \\
\text { information resource }\end{array}$ \\
\hline $\begin{array}{l}\text { receiving often material } \\
\text { remuneration according to } \\
\text { the result of the } \\
\text { performance of their duties }\end{array}$ & $\begin{array}{l}\text { feeling of being } \\
\text { included in a certain } \\
\text { circle of "elected", } \\
\text { possessing special } \\
\text { knowledge }\end{array}$ \\
\hline $\begin{array}{l}\text { possession of special } \\
\text { powers, which, at least, are } \\
\text { determined by the status of } \\
\text { the active member of the } \\
\text { local virtual group. }\end{array}$ & $\begin{array}{l}\text { certain rights and } \\
\text { obligations that can } \\
\text { directly affect the } \\
\text { stability of the existence } \\
\text { and development of a } \\
\text { local network group }\end{array}$ \\
\hline
\end{tabular}

Users included in the stratum "creators of software resource and content" often believe that they have sacred knowledge and skills that are accessible only to a very tiny number of people. They differently (in comparison with other members of the local virtual group) perceive the features of the existence of a local Internet group and at the same time regularly emphasize the low level of competence of other members of virtual society, primarily of common users.

"Users" stratum. The said stratum is characterized by factors, specified in Table 3.

Table 3. Characteristics of stratum "users".

\begin{tabular}{|c|c|}
\hline \multicolumn{2}{|c|}{ Factors } \\
\hline objective & subjective \\
\hline $\begin{array}{l}\text { potential for regular and } \\
\text { systematic access to } \\
\text { information content }\end{array}$ & $\begin{array}{l}\text { feeling of involvement in } \\
\text { the social environment, } \\
\text { world of progressive it- } \\
\text { technologies and Internet } \\
\text { communities }\end{array}$ \\
\hline \multirow{3}{*}{$\begin{array}{l}\text { opportunity to take a direct } \\
\text { part in the existence and } \\
\text { development of a local } \\
\text { Internet community: } \\
\text { a) opportunity to create } \\
\text { various topics, series, } \\
\text { message board, } \\
\text { b) exchange of varying } \\
\text { information with other users } \\
\text { of the Internet community, } \\
\text { c) making requests to the } \\
\text { owners of Internet resources, } \\
\text { d) initiation of collective } \\
\text { actions, as well as offline } \\
\text { meetings }\end{array}$} & $\begin{array}{c}\text { broadening of range of } \\
\text { interests and inception of } \\
\text { new information and } \\
\text { heuristic needs }\end{array}$ \\
\hline & $\begin{array}{l}\text { social ascent from the } \\
\text { members which form in } \\
\text { the virtual environment a } \\
\text { local network society }\end{array}$ \\
\hline & $\begin{array}{l}\text { the need to get rid of } \\
\text { hunger for information, to } \\
\text { express game appeal, } \\
\text { desire to express various } \\
\text { emotions, etc. }\end{array}$ \\
\hline
\end{tabular}

We have already mentioned that various local Internet communities have similar stratified systems. Next, we will consider in more detail the stratified structure of the most widespread form of local virtual communities.

\section{Stratified structure of local virtual communities}

Different forums have their own codes of rights and responsibilities, in which the existing stratums consolidate their positions. The hierarchy of the most important stratums in the stratified scale is shown in Fig. 2.

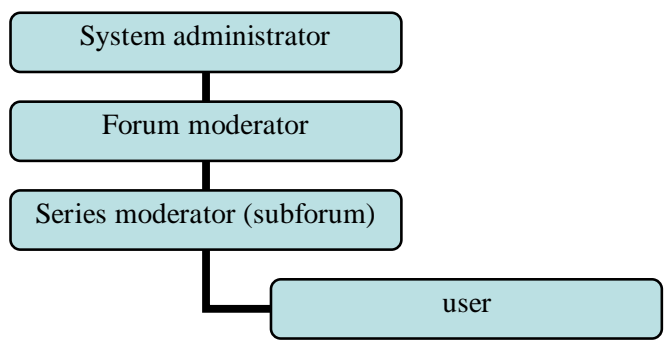

Fig. 2. Hierarchy of the most important stratums in the stratified scale. 
Let us turn our attention to social statuses identified in this stratified structure. System administrators have the highest status, both in terms of qualification, and in purely technical terms. Representatives of this stratum regularly monitor social interactions of members of related to them local network groups, and ensure uninterrupted access to resources, security of the software environment, establish the level of users' access to various types of information resources, and also control whether the moderators fulfill their functional responsibilities. Usually these powers, as well as the power to approve administrators, have either the owners of the Internet. The actions of users in the Internet is a ban, when the user forfeits or is restricted any right (to create / send new messages or create new topics on the web forum, send messages in the chat, comment on blogs, etc.). This opportunity is introduced in order to protect the Internet community from trolls, spammers, vandals and other persons whose messages are harmful to the productive work of the resource. Ban is a "strict measure" and can be used by resource owners as a means of protection from users who express the views that dislikes the owners of the resource, which can provoke vandalism or war of bots, and even hacker attacks in order to remove the resource or change it beyond recognition.

Some network communities have a procedure for users preselection - pre-moderation. The mechanism of premoderation consists in the following: a potential member of the local Internet community fills in a special form, and in the event that the specified data satisfy the moderator, an email with confirmation of registration is sent to the new user for e-mail. In the study, the authors faced various and ambiguous manifestations of moderation, in some cases up to the application of double standards. However, it should be noted that information load on moderators is truly heavy and moderation of local virtual groups with low entry barriers and where the number of members is counted in thousands is quite a difficult task.

Moderator completely controls the forum content. His main goal is to attract the maximum number of users to the ongoing discussion [2]. Moderator is responsible for social ordering of the Internet community entirely or in one of its sections, series; its main task is to develop the communication activity of the members of the network society and solve problems arising at the organizational, technical or interpersonal level. In most cases, moderator is one of the members of the Internet community selected by other users. Users who want to become moderators of the online community usually motivated by an extensive (at the hobby level) or professional knowledge of the subject of the online community; interest of owners of sites similar in content on which there are no forums; the desire of members to expand their circle of contacts, their desire to share knowledge and experience with other users.

Comparative analysis of the basic properties and characteristics of status positions conducted by the authors shows the significance for the stratified system of the criteria that are essential in the value system of this network community. It is important to stress, that stratification within local virtual groups is systemic, since in the absence of it a social order is impossible. However, the stable functioning of the Internet community is not possible without a stratified system as a form of institutionalization of social action. Social order can be organized both through self-government and through directive methods.

According to the research of M.A. Smith, who in the nineties analyzed the specifics of communication among the members of one of the first Internet communities WELL, only $1 \%$ of the total number of members of the virtual group are the authors of more than $50 \%$ of all included in the number of members of local Internet communities not only by researchers: in social survey, interviewees from the lurkers group certainly declared that they subjectively feel full involvement in the network society. As a rule, such individuals are usually sensitive to potential exclusion from the network community. However, some passive users with sufficient experience, fresh ideas and knowledge are valued members of the community: some conditions can motivate them to active involvement in the life of the Internet community. Such "activation" of passive members is a significant indicator of the special professionalism of the leaders of virtual group. Thus, "lurkers" are a stable, but at the same time communicatively passive group of users of local Internet communities. This behavior can be interpreted as asocial, since the absence of user activity can lead to the break up of the network community. But such stratum of users exists and, of course, must be reported.

\section{Conclusions}

On the basis of generalization of theorizes and processing of the data received, the authors come to the conclusion that there is a stratified scale in any local community according to which the users are ranged.. The study of the behavior of individuals in a virtual environment indicates that generally the members of local network communities prefer not to create information, but rather to consume it. In the stratified scale of a local network society (forum) they make up a fairly extensive group in the "users" stratum. Thus, according to the stratified criterion "involvement activity" the stratum "users" is divided into "passive" and "active" ones. The Internet survey showed that in the process of socialization for the majority of new members $(40 \%)$ a week was enough to learn the stratification structure and adopt the basic laws of interaction in the local Internet community. It should be noted that the experts interviewed by us unanimously pointed out that the share of "new members" in the local Internet communities is nearly always very significant and it is a basis for further rotation in experienced members. The share of new members in the studied local Internet communities was a little under $45 \%$ of respondents. The overwhelming majority of members of local Internet communities recognize the presence of leaders in virtual online societies. Internet survey conducted by the author showed that more than $73 \%$ of 
the respondents recorded the presence of leaders in local Internet communities. At the same time, all the respondents who took part in the expert survey also affirmed the presence of leaders in the local Internet community. However, the stable functioning of the Internet community is not possible without a stratified system as a form of institutionalization of social action. Described stratified scales of members of local Internet communities can be applied for the purpose of practical analysis of the processes of social regulation of local Internet communities.

\section{References}

1. C. Bildt, G. Smith, Journal of Cyber Policy 1(2), 142-156 (2016)

2. G. Collison, G. Elbaum, S. Haavind, R Tinher, Facilitating online learning - effective strategies for moderators (Madison, WI: Atwood Publishing, 2000)

3. D. Horton, Environmental Politics 13(4), 734753 (2010)

4. J. Glaser, Producing Communities as a Theoretical Challenge (TASA Conference. -Sydney, Australia, Dec 13-15, 2001)

5. M. J. Stern, Communication \& Society 11(5), 591-616 (2008)

6. M. Saayman, R. Rossouw, A. Saayman, Development Southern Africa 29(4), 588-609, (2012)

7. T. A. Parsons, Revised analytical approach to the theory of social stratification (Glencoe: The Free Press, 2 ed., 1964)

8. P. M. Napoli, S. Stonbely, K. McCollough, B. Renninger, Journalism Practice, 11(4), 373-395 (2016)

9. S. D. Houston, K. Lange, Journal of Geography in Higher Education 42(1), 44-60 (2017)

10. J. Slevin, The internet and society (Cambridge: Polity Press, 2000)

11. M.A. Smith, Voices from the WELL: the logic of the virtual commons (Usyd.edu., 1992) 